\title{
An Innovative Approach to Repair Perforating External Root Resorption in a Chronically Infected and Pulpless Incisor - A Case Report
}

\author{
Asaad Javaid Mirza ${ }^{1, *}$, Mohammad Khalid Shafiq ${ }^{2}$, Maaz Asad javaid ${ }^{3}$, Marwah Berkathullah Shariff ${ }^{3}$ \\ ${ }^{1}$ Department of Operative Dentistry, Peshawar Dental College, Peshawar, Pakistan \\ ${ }^{2}$ Department of Operative Dentistry, Baqai Dental College, Karachi, Pakistan \\ ${ }^{3}$ Department of Restorative Dentistry, University of Malaya, Kuala Lumpur, Malaysia \\ *Corresponding author: asaadjmirza@gmail.com
}

Received August 05, 2014; Revised August 15, 2014; Accepted August 19, 2014

\begin{abstract}
This is a case report of a young boy who had a physical trauma to his right maxillary central Incisor. As it remained untreated for many years, it underwent severe inflammatory external root resorption causing perforation. The root of the tooth was damaged to an extent that extraction of the tooth was indicated. But keeping the site of the tooth, age of the patient and his interest in saving the tooth in view, we decided to take a chance to save the tooth in an innovative manner. Firmness of the tooth in its socket also motivated us to opt for a restorative treatment instead of referring him to surgery for extraction. A hopelessly damaged tooth which was very much indicated for extraction has been saved which satisfies patient's cosmetic demands on lower cost. He otherwise, would have to bear the cost of either 3-unit Bridge or Implant supported crown. Quarterly radiographic examination shows progressive apical and periodontal healing after the treatment since last six months.
\end{abstract}

Keywords: root resorption repair, external root resorption

Cite This Article: Asaad Javaid Mirza, Mohammad Khalid Shafiq, Maaz Asad javaid, and Marwah Berkathullah Shariff, "An Innovative Approach to Repair Perforating External Root Resorption in a Chronically Infected and Pulpless Incisor - A Case Report.” International Journal of Dental Sciences and Research, vol. 2, no. 4 (2014): 99-102. doi: 10.12691/ijdsr-2-4-7.

\section{Introduction}

External root resorption is a destructive process that leads to loss of hard tissues of a tooth covering its roots. It occurs on outer surface of permanent teeth due to resorptive activity of osteoclast and odontoclast cells [1]. External root resorption may be of types and is classified as external inflammatory resorption, external surface resorption, external replacement resorption (ankylosis), external cervical resorption and transient apical breakdown [2]. External inflammatory root resorption is the commonest among them [3]. Each of this resorption occurs after trauma to the covering hard tooth tissues followed by stimulation either through infection or pressure [4]. Various causes of root resorption include; mechanical trauma, luxation injury, orthodontic tooth movement and chronic pulp or root canal space infection [5].

The present case had massive external root resorption on right maxillary central incisor (tooth \# 11) which remained untreated for many years after trauma. Though necrosed pulp had been removed two years ago but the resorption did not stop as pulp canal space was not thoroughly debrided and hermetically sealed. The canal remained infected and became a long lasting stimulus for inflammatory root resorption [6]. The logical reason for this resorption may be that the trauma to affected tooth caused injury to cementum with consequent loss of its protective function. It allowed bacteria and its toxins to pass through dentinal tubules to periodontium stimulating inflammatory response leading to Lateral Periodontitis with root resorption [7].

Normally, teeth with external root resorption should be root filled before surgical correction of the resorptive defect. It was not possible in this case because of extensive root resorption. We therefore, decided to perform surgical procedure first and to seal and fill the canal with Glass Ionomer Cement through retrograde approach later.

\section{Case Report: History}

A 21- year old patient, student by profession presented with the complaint of his blackened ugly looking central incisor. He also complained of salty taste of his mouth many times a day. His medical history was non contributory. Dental history revealed that the patient received an external blow on his right maxillary central incisor in his childhood during a football match. As long as the tooth remained asymptomatic the patient did not feel the need of seeking any consultation or treatment. But 
once the tooth became symptomatic, he went to a dentist who initiated root canal treatment of the affected tooth two years ago. Surprisingly, it was incomplete at the time he reported to us. The poor patient was unaware of the reason for the delay in his treatment.

On examination, no facial abnormality was detected extra-orally. Intra-orally all of his teeth were found present with poor oral hygiene but normal occlusion. Tooth \# 11 was slightly tender to vertical percussion and palpation on buccal aspect. There was puss discharge seen from apical area of tooth \# 11 in labial sulcus. The tooth was highly discolored compromising his esthetics and half broken but firmly fixed in its socket. Pocket depth at all sites around the tooth was normal. Previous dentist had filled coronal access with some temporary material. A temporary filling was also seen in the cervical area of labial surface of tooth \# 11 (Figure 1).

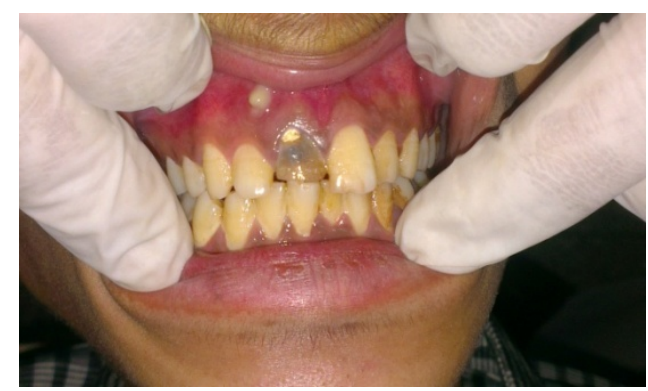

Figure 1. Tooth \#11 Half broken \& showing discoloration and cervical packing

Radiographic examination revealed a big radiolucency lateral to the middle of root of tooth \# 11 on mesial side. There was extensive lateral and apical root resorption associated with the radiolucency. Diagnostic file passed through the resorbed (perforated) area and entered into the lesion without any hindrance (Figure 2).

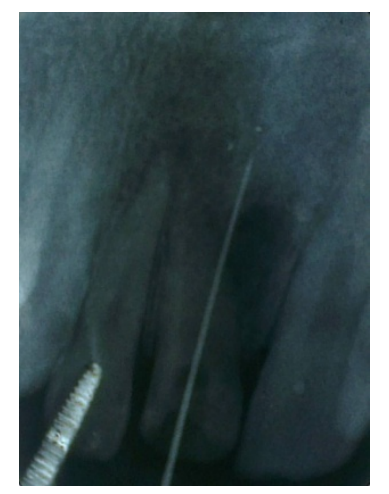

Figure 2. A big radiolucent lesion seen involving mid-radicular and apical area of \# 11

Patient was briefed about the hopeless condition of his affected tooth. He already knew it and was interested to get it extracted. But when it was explained that remote chances exist to save the tooth through a surgical procedure otherwise the tooth would be extracted. He readily gave his consent to attempt the surgical procedure.

\section{Treatment}

After scaling and polishing, a trapezoidal flap was raised to expose the defect in the root (Figure 3). The defect was confirmed by passing $\mathrm{K}$ file \#25 and seen clinically passing through the perforation. All the granulation tissues were removed with surgical curette from mid radicular and cervical areas. Damaged apical part of the root was resected and root margins were smoothened and made such that access inside the canal was easy for us to obturate it (Figure 4).

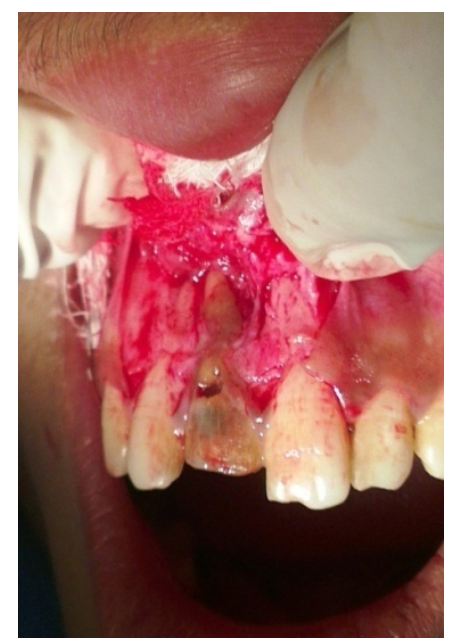

Figure 3. Flap raised and cervical packing removed

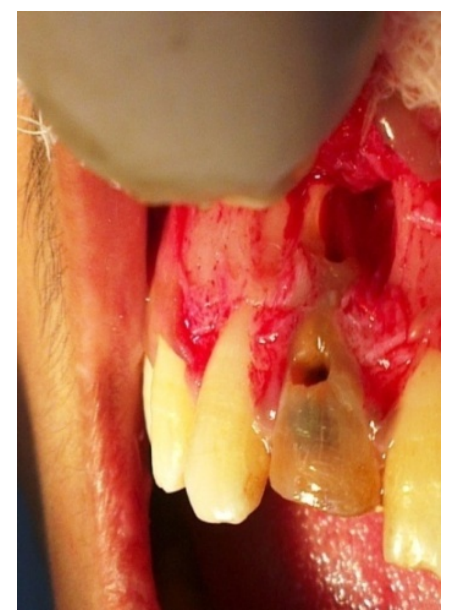

Figure 4. Granulation tissues removed and access into the canal faciltated

The canal was prepared using Gates \#3 and 4. Head of the Gates was visible apically during preparation. It helped in controlled preparation avoiding unnecessary cutting. $2.5 \%$ Sodium Hypochlorite was used copiously for irrigation of the canal. The canal was then dried using sterile gauze wrapped on a file as paper point of matching size of the preparation was not available.

The cervical defect was repaired with Glass Ionomer Cement Type II (GC Corporation, Tokyo, Japan) of thick consistency. A flowable consistency of same Glass Ionomer Cement was then loaded in an empty syringe of Calcium Hydroxide (Figure 5) and placed into the prepared canal through the cut apex of the root until the canal overflowed [8]. This overflowing material was used to repair external surface of the root (Figure 6). During pouring care was taken that no air bubble traps in the canal. The flap was sutured back in place and postoperative X-ray taken (Figure 7). After a week, the sutures were removed. On next appointment, four weeks later, 
when clinically everything was found normal, porcelain fused to metal crown was cemented (Figure 8).

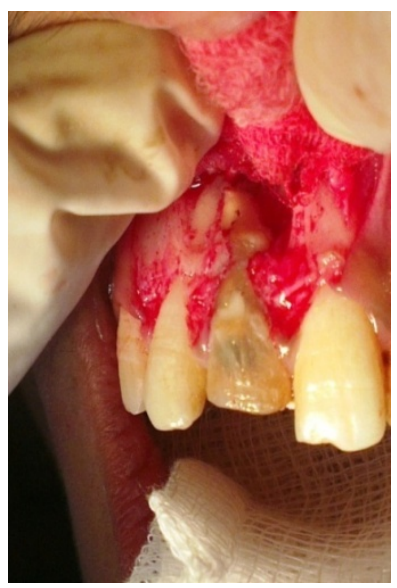

Figure 5. Empty Syringe of calcium Hydroxide used for placing GIC into the canal

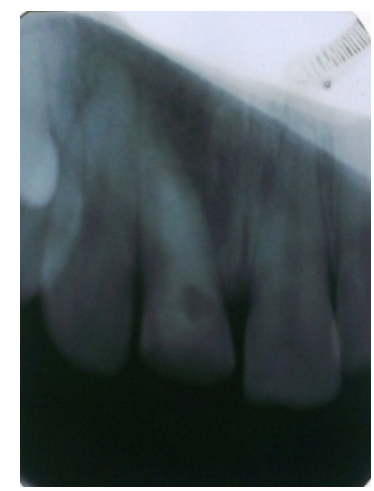

Figure 6. Slight resection of apex with cervical defect repaired and GIC overflowing

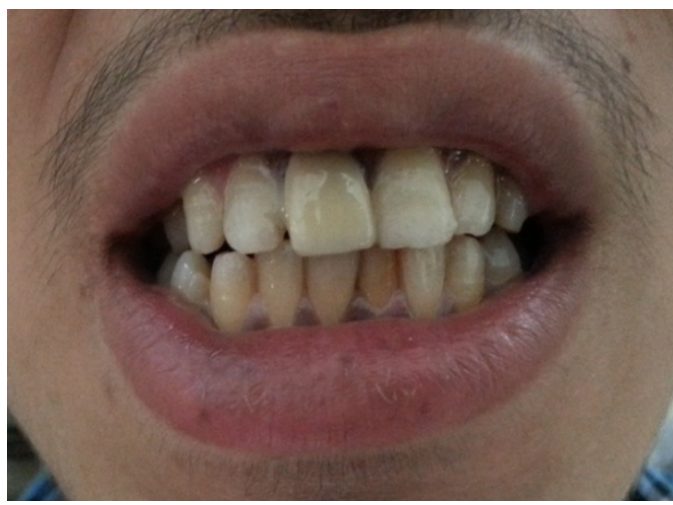

Figure 7. Post Operative X-ray right after surgery

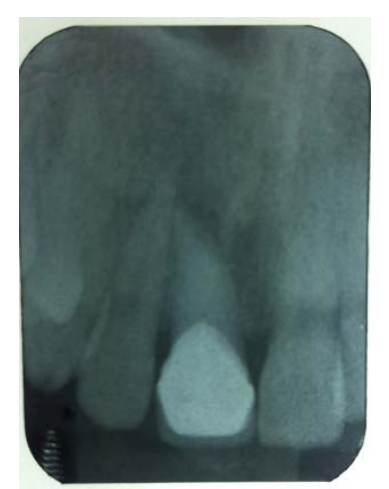

Figure 8. Porcelain fused to metal crown in place
The patient visits us quarterly and X-ray shows progressive healing of the radiolucent lesion around the root (Figure 9).

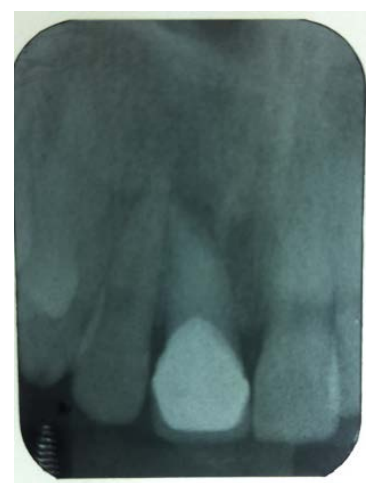

Figure 9. X-ray after 6 months showing bone formation (reduced radi

\section{Discussion}

Cementum and predentin are protective layers against root resorption [9]. A traumatic injury to a tooth induces inflammatory reaction which may cause little to massive root resorption and surrounding bone destruction depending upon the length of time for which the resorption stimulus (inflammatory response) stays there [10].

In this case the root canal space remained infected for many years and caused resorption along the external surface of the root to an extent that blind preparation and orthograde obturation was not possible. The surgical procedure therefore, was performed first. Once the flap was raised and all granulation tissues and apical part of the tooth was removed, retrograde access to the tooth became clearly visible. It allowed easy canal preparation and obturation.

For obturation, Gutta Percha points were found unsuitable due to massive tooth destruction. In its place, a material was required which could flow well from apical to coronal part of the root and can seal the dentinal tubules. Glass Ionomer is such a material which has good flowing and perfect sealing ability. It also works as space filler as it tends to occupy available space.

For repair of resorption, a material was needed that must be biocompatible not only to teeth but bone as well so that could be safely placed in direct contact with the bone. Many materials like silver amalgam, composite, Mineral Trioxide Aggregate are used for this purpose. Glass Ionomer fulfilled our requirement also, as it is biocompatible and has long been used for repair of bony defects in head and neck, periodontal furcation defects, bone regeneration \& as a bone substitute [11,12,13,14]. Moreover, Glass Ionomer when used for retrograde filling was found to have less micro leakage and less cytotoxicy [15]. Keeping these properties of Glass Ionomer in view, it was used in this case in an innovative manner.

The salty taste of patient's mouth was most probably due to puss discharge into his mouth. As there was no puss discharge after wound healing, the patient did not complain of that salty taste. 
Use of right technique and appropriate selection of material may save many such teeth which clinically or radiographically appear hopelessly destructed due to external root resorption and are extracted.

\section{References}

[1] Bergmans L, Van Cleynenbreugel J, Vergeken E, Wevers M, Van Meerbeck B, Lambrechts P. Cervical external root resorption in vital teeth. J Clin Periodontol 2002; 29(6): 580-585.

[2] Patel S, Kanagasingam S, Pitt Ford T. External cervical resorption: A review. J Endod 2009; 35: 616-25.

[3] Vineet SA, Sonali K. Clinical management of severe external root resorption and immature open apex with MTA and calcium hydroxide - A case report. Endodontology [online] 83 - 88 available from: http://medind.nic.in/eaa/t11/i2/eaat11i2p81.pdf accessed on 8.8.2014.

[4] Fus Z, Tseis I, Lin S. Root resorption - diagnosis, classification and treatment choices based on stimulation factors. Dental Traumatology 2003; 19: 175-182.

[5] Elisabeth Nilsson, Eric Bonte, François Bayet, Jean-Jacques Lasfargues. Management of Internal Root Resorption on Permanent Teeth. International Journal of Dentistry 2013; (2013): 1-7.

[6] Trope M. Root Resorption due to Dental Trauma. Endodontic Topics 2002; 1: 79-100.

[7] Andreasen JO. Periodontal healing after replantation of traumatically avulsed human teeth. Assessment by mobility testing and radiography. Acta Odontol Scand 1975; 33: 325-332.
[8] Clarissa CB, Daniela H, Marcelo B, Cor V L, Amerongen WE Van, Daniela PR. A preliminary clinical trial using flowable glassionomer cement as a liner in proximal-ART restorations: The operator effect. Med Oral Patol Oral Cir Bucal. 2013; 18(3): e529e532.

[9] Hammarstrom L, Lindskog S. General morphologic aspects of resorption of teeth and alveolar bone. Int Endod J 1985; 18: 293298.

[10] Olivieri JG, Duran-Sindreu F, Mercadé M, Pérez N, Roig M. Treatment of a perforating inflammatory external root resorption with mineral trioxide aggregate and histologic examination after extraction. Endod 2012; 38(7): 1007-1011.

[11] Doherty, P. J. Biocompatibility evaluation of Glass Ionomer Cement using cell culture techniques. Clin Mater 1991; 7 (2): 335340.

[12] Cole I, Dan N, Anker A. Bone replacement in head and neck surgery: a biocompatible alternative. Aust N Z J Surg. 1996; 66(7) 469-472.

[13] Singhal R. Glass Ionomer cement as an occlusive barrier in Class III furcation defect. Indian J Dental Research 2011; 22 (4): 583586.

[14] Salata LA, Sverzut CE, Xavier SP. Recent advances in the use of Glass Ionomers: bone substitutes. Rev Odontol Univ [online]1999; 13(2): available from: http://www.scielo.br/scielo.php?script=sci_arttext\&pid=S010306631999000200016Accessed on 6.8.2014.

[15] Pissiotis E, Sapounas G, Spångberg LS. Silver Glass Ionomer cement as a retrograde filling material: a study in vitro. J Endod 1991; 17(5): 225-229. 